\section{GORDON PIKE}

One of the most demanding tasks a member of the Materials Research Society can accept is chairmanship of the Annual Meeting. The intellectual challenge of orchestrating a cohesive and comprehensive technical conference, particularly an interdisciplinary one, is matched by the challenge of organizing and administering the thousands of mechanical details that attend such a conclave. The Co-chairman of the 1983 Annual Meeting, Gordon Pike, Sandia National Laboratories, helped deliver the most successful such meeting in the Society's history-and then, only a few months later, served in a similar capacity for the MRS's inaugural Spring Meeting. Now, as Chairman of the Society's Program Committee, Gordon has performed a kind of MRS hat-trick, assuming a range of responsibility over technical programming unique in the Society's history. The Society's phenomenal growth in the last two years is a reflection of the quality of its

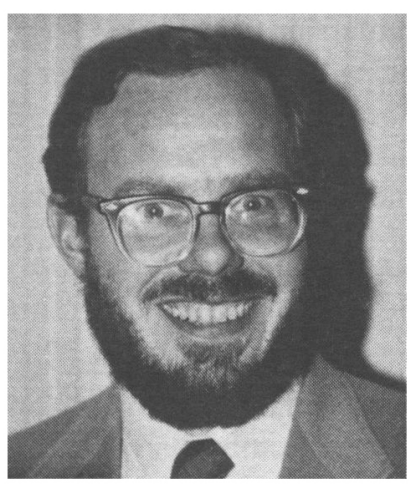

GORDON PIKE meetings, which owe very much to the imagination and determination of Gordon Pike.

\section{Gordon E. Pike}

Gordon E. Pike was graduated from Carnegie-Mellon University in 1963 with a B.S. in physics. He received his $\mathrm{Ph} . \mathrm{D}$. in solid state physics from the University of Pittsburgh in 1969. That year he began his association with Sandia National Laboratories, where he worked in the general area of electrical properties of materials. He has made experimental and theoretical contributions in the fields of electronic hopping transport in insulators, superconductivity, radiation effects in MOSFET transistors, percolative conduction in heterogeneous materials, and the electronic properties of semiconductor grain boundaries.

At the 1981 MRS Annual Meeting, Gordon served with distinction as co-chairman of the Grain Boundaries in Semiconductors symposium. His co-workers discovered that his zeal for science was matched by a willingness to accept responsibility for every aspect of a meeting's management. $\mathrm{He}$ became increasingly active in the Society's affairs, and his contributions increasingly valuable to the Society's success.

\section{'MRS Strongman'}

One of his many friends in the MRS, Past President Harry Leamy of AT\&T Bell Laboratories, notes: "Gordon Pike is a true MRS strongman. He and I first worked

\section{VAN TRAN NGUYEN}

The MRS has grown and prospered not only because it serves the unique needs of materials researchers but also because a relatively small number of enthusiasts have devoted much of their own thought, time, and energy to the MRS and have been able to convince their institutions to support the Society as well. Elsewhere in these pages, the central role of Paul Siffert of CNRS, Strasbourg, has been pointed out. Another "founding father" of the MRS-Europe effort is Van Tran Nguyen.

\section{Van Tran Nguyen}

Van Tran was born in Viet Nam in 1933 and emigrated

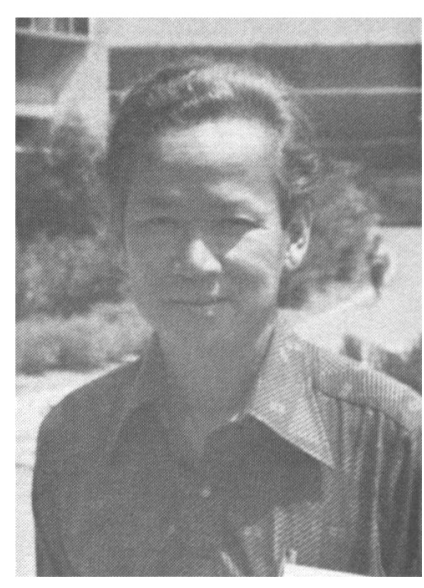

VAN TRAN NGUYEN to France in the 1950s, where he graduated from the Ecole National Superieure des Telecommunications in 1960. He spent the next seven years with Thomson-CSF and C.G.E. research centers in France, where he pursued graduate work in the field of nonlinear interactions of microwaves and light with matter. In 1967, he joined Bell Laboratories in Holmdel, New Jersey, devoting his studies to infrared physics, nonlinear optics, and spin-flip Rama lasers. His latest move took him back to France in 1979, where he is now Director of the Physics and Technologies Division of the CNET Microelectronics Research Center in Grenoble.

In attending MRS meetings in Boston, Van Tran saw an opportunity for the production of multidisciplinary forums for materials research. He is now adding his talents and those of his institution to the efforts of his European colleagues toward the objective of creating an MRS adapted to the special needs of the European scientific community. The success of this June's meeting in Strasbourg is ample evidence that these dedicated supporters of the MRS idea are finding the right formula.

together to organize an MRS symposium on grain boundaries, and it was during this collaboration that I discovered his marvelous capacity for organization, and his good judgment. During subsequent years I have watched with admiration as he exercised his skills as meeting cochairman, both in the Fall meeting, and again in our first Spring meeting. The record is clear; Gordon Pike has provided the MRS with invaluable leadership during the last three years. I regard both myself and the MRS as fortunate to have had the pleasure of working with him." 